\title{
Dosimetry in Micro-computed Tomography: a Review of the Measurement Methods, Impacts, and Characterization of the Quantum GX Imaging System
}

\author{
Jeffrey A. Meganck, ${ }^{1}$ Bob $\mathrm{Liu}^{2}$ \\ ${ }^{1}$ Research and Development, Life Sciences Technology, PerkinElmer, 68 Elm Street, Hopkinton, MA, 01748, USA \\ ${ }^{2}$ Department of Radiology, Massachusetts General Hospital, Boston, MA, USA
}

\begin{abstract}
Purpose: X-ray micro-computed tomography $(\mu \mathrm{CT})$ is a widely used imaging modality in preclinical research with applications in many areas including orthopedics, pulmonology, oncology, cardiology, and infectious disease. X-rays are a form of ionizing radiation and, therefore, can potentially induce damage and cause detrimental effects. Previous reviews have touched on these effects but have not comprehensively covered the possible implications on study results. Furthermore, interpreting data across these studies is difficult because there is no widely accepted dose characterization methodology for preclinical $\mu \mathrm{CT}$. The purpose of this paper is to ensure in vivo $\mu \mathrm{CT}$ studies can be properly designed and the data can be appropriately interpreted.

Procedures: Studies from the scientific literature that investigate the biological effects of radiation doses relevant to $\mu \mathrm{CT}$ were reviewed. The different dose measurement methodologies used in the peer-reviewed literature were also reviewed. The CT dose index $100\left(\mathrm{CTDI}_{100}\right)$ was then measured on the Quantum GX $\mu \mathrm{CT}$ instrument. A low contrast phantom, a hydroxyapatite phantom, and a mouse were also imaged to provide examples of how the dose can affect image quality.

Results: Data in the scientific literature indicate that scenarios exist where radiation doses used in $\mu \mathrm{CT}$ imaging are high enough to potentially bias experimental results. The significance of this effect may relate to the study outcome and tissue being imaged. CTDI ${ }_{100}$ is a reasonable metric to use for dose characterization in $\mu \mathrm{CT}$. Dose rates in the Quantum GX vary based on the amount of material in the beam path and are a function of X-ray tube voltage. The CTDI ${ }_{100}$ in air for a Quantum GX can be as low as $5.1 \mathrm{mGy}$ for a $50 \mathrm{kVp}$ scan and $9.9 \mathrm{mGy}$ for a $90 \mathrm{kVp}$ scan. This dose is low enough to visualize bone both in a mouse image and in a hydroxyapatite phantom, but applications requiring higher resolution in a mouse or less noise in a low-contrast phantom benefit from longer scan times with increased dose.

Conclusions: Dose management should be considered when designing $\mu \mathrm{CT}$ studies. Dose rates in the Quantum GX are compatible with longitudinal $\mu \mathrm{CT}$ imaging.
\end{abstract}

Key words: X-ray micro-computed tomography, Half value layer (HVL), Radiation dose

Correspondence to: Jeffrey Meganck; e-mail: jeff.meganck@perkinelmer.com

\section{Introduction}

The field of medical imaging utilizes many different imaging and detection methodologies. Magnetic resonance imaging, 
ultrasound, and optical imaging do not use ionizing radiation, and are generally considered to be safe. However, radiation dose can become a concern in the nuclear and X-ray-based imaging modalities that use ionizing radiation. Ionizing radiation can have a range of acute, latent, and genetic effects with clinical outcomes ranging from mild sickness to sterility to acute illness with early death [1]. Previous reviews have also investigated clinically relevant radiation-induced cancer and skeletal changes that can occur $[2,3]$.

$\mathrm{X}$-ray micro-computed tomography $(\mu \mathrm{CT})$ is an imaging modality that is widely used to image both hard and soft tissues for studies in orthopedics, pulmonology, oncology, cardiology, radiology, and infectious disease [4-7]. By directing the X-ray beam at tissue and placing a detector on the opposite side, an image can be created that is directly related to the absorption and scatter within tissue (due to the photoelectric effect and Compton scatter) that leave energy behind in the tissue, creating the dose. Unfortunately, there is no single accepted unit for X-ray dose. Previous studies have used Roentgens (R), Sieverts (Sv), Gray (Gy), radiation absorbed dose (rad), and Roentgen equivalent man (REM) $[1,8]$. Irrespective of which unit is used, several fundamental physical concepts contribute to dose. The inverse square law states that dose is inversely proportional to the square of the distance between the source and object. The linear attenuation coefficient is energy dependent, and commonly used sources have a polychromatic X-ray spectrum, so dose is proportional to the sum of all photons absorbed at energies in the spectrum being used. Mathematically, combining these gives the following relationship:

Total dose $\propto \frac{\sum_{\mathrm{Emin}}^{\mathrm{Emax}} N_{E}(L, \mu(E))}{r^{2}}$

where

$E=$ X-ray photon energy

$r=$ distance between source and object

$N_{\mathrm{E}}=\#$ of absorbed photons for a given energy

$L=$ path length that $\mathrm{X}$-rays travel through tissue

$\mu(E)=$ linear attenuation coefficient

The inclusion of $L$ and $\mu$ in this relationship indicates that there is some dependence on the object itself. The linear attenuation $\mu(\mathrm{E})$ is tissue dependent. Materials with a higher electron density will attenuate more [9]. Due to the $L$ term, smaller objects will tend to have a higher mean dose at the isocenter because of the shorter path length between the center and outside air, but still have a lower total absorbed dose because of the shorter total path length [10].

Beyond this conceptual relationship, there are many sources of noise in X-ray systems that must be considered in practice to achieve the desired image quality for a given application. The simplest explanation based on statistics (SNR $\propto \sqrt{N}$, where SNR is the signal to noise ratio and $N$ is the number of photons) dictates that dose must increase as the total number of pixels increases to maintain a given per-pixel SNR. More complex models that incorporate a full set of system parameters have shown this to be true [11]. Therefore, guidelines exist to navigate the different tradeoffs (e.g., [12]). In practice, one of the best ways to design imaging protocols is to use phantoms to find the right balance between an acceptable SNR, resolution and dose with the overarching principal of using a dose as low as reasonably achievable (ALARA) [5, 13-16].

Understanding the biological response to radiation is obviously crucial to design longitudinal studies that require ionizing radiation. Fortunately, a number of excellent reviews have been written on the molecular mechanisms governing the response. X-rays can interact with any molecule and, therefore, can cause both short-term and long-term harm. X-ray interactions with water can create reactive oxygen species (ROS) and free radicals which have a number of potential effects on cellular behavior [17]. X-rays can also interact with genetic material and can directly induce damage foci that can be detected with markers such as ATM (ataxia telangiectasia mutated), 53BP1 (p53 binding proten 1), and $\gamma \mathrm{H} 2 \mathrm{AX}$ (a phosphorylated version of histone H2AX) [18]. ATM and $\gamma \mathrm{H} 2 \mathrm{AX}$ are part of complex signaling cascades leading to DNA repair by homologous recombination (HR) or non-homologous end-joining (NHEJ) processes [19, 20], and these signaling cascades can also be impacted by micro-RNAs [21]. Even lowdose radiation hypersensitivity (defined as doses below $0.3 \mathrm{~Gy}$ ) can affect both DNA repair and the cell cycle [22]. Therefore, it is not surprising that $\mu \mathrm{CT}$ scans with doses as low as $150 \mathrm{mGy}$ in mice have been reported to induce double-strand DNA breaks [23]. Fortunately, some of these double-strand breaks will start to repair in the initial minutes post radiation and may be largely repaired within the first day, although immune competent $\mathrm{C} 57 \mathrm{Bl} / 6$ mice repair more damage than severe combined immune deficient (SCID) mice [23, 24]. Disruptions to the HR and NHEJ signaling cascades or processes could alter these rates.

For preclinical X-ray imaging, it is generally believed that the LD50/30 (the dose lethal to $50 \%$ of the subjects within 30 days) for rodents is in the range of 5-7.6 Gy [11], although this may be reduced to 3 Gy in SCID strains [25]. Radiosensitivity is also dependent on animal strain [26]. Given the complex interplays between physics and biology outlined above, even formal animal welfare guidelines do not provide actual numbers and simply state that doses should be minimized [27]. It is important to look at dose on a tissue by tissue basis and, in some cases, on a study by study basis to understand the potential acute and longer-term impacts.

\section{Dose Effects: Lung Applications}

Lung tissue may not be particularly susceptible to the high doses common in conventional fractionated radiotherapy and 
frequent $\mu \mathrm{CT}$ scanning. Immunocompetent C57/B16 mice scanned three times per week for a 6 -week period, with a total cumulative dose of $5.04 \mathrm{~Gy}$, do not have a difference in lung parenchyma volume or Hounsfield unit (HU) value [28]. Similarly, doses on the order of 5-12 Gy delivered to the lung over 5 weeks, or 12 Gy over 12 weeks, do not result in a change in aerated lung volume, lung tissue volume, total lung volume, or gross histopathological change in immunocompetent C57Bl/6 mice [29]. However, very high doses for lung imaging could still be problematic. One week after delivery of a 90 Gy dose to the lungs of immunocompetent $\mathrm{C} 57 \mathrm{Bl} / 6$ mice for sterotactic body radiotherapy there is no noticeable change in gross morphology or lung structure on a $\mu \mathrm{CT}$ image, although there is histopathological damage that will eventually lead to fibrosis and altered lung function as early as 2-3 weeks later [30]. The 30 Gy dose threshold to induce this fibrosis in immunocompetent $\mathrm{C} 57 \mathrm{Bl} / 6$ mice is slightly lower for than the 50 Gy needed to induce fibrosis for immunocompetent $\mathrm{C} 3 \mathrm{H}$ mice [31]. A single $20 \mathrm{~Gy}$ dose to the lungs of immunocompetent $\mathrm{C} 57 \mathrm{Bl} / 6$ mice does not cause a change in lung volume manually measured on a $\mu \mathrm{CT}$ image after 4 days, but the $\mathrm{HU}$ value shifts and air spaces are enlarged [32]. However, the simple image analysis methods typically used for lung studies may not be adequate to detect all of the changes that are visible in $\mu \mathrm{CT}$ images. A variogram-based image analysis approach may be needed to capture the effects of 6-15 Gy doses [33]. Most importantly, since lung imaging is often used for cancer studies, an investigator must keep in mind that specific genetic mutations can have differential effects. As one example, the presence or absence of a tumor suppressor gene in mice impacts susceptibility to the difference between a single 11.6 Gy dose and a fractionated 14.6 Gy dose delivered over 2 days [34].

\section{Dose Effects: Bone and Orthopedic Applications}

Bone tissue has a higher linear attenuation coefficient than soft tissues and experiences local doses approximately 3-5 times higher than lung tissue $[29,35,36]$. Therefore, many studies have investigated the effects of ionizing radiation on bone in a variety of environments. Within the context of a radiation accident, a single 8 Gy dose of ${ }^{60} \mathrm{Co}$ irradiation to immunocompetent B6D2F1/J mice induces weight loss, decreases trabecular bone volume fraction and reduces the bone formation rate as long as 120 days post-exposure [37]. In the context of spaceflight, a 1-2 Gy dose of common particles (gamma rays, protons, ${ }^{12} \mathrm{C}^{6+},{ }^{56} \mathrm{Fe}^{26+}$ ) to immunocompetent $\mathrm{C} 57 \mathrm{Bl} / 6 \mathrm{~J}$ mice decreases the trabecular bone volume fraction and volumetric bone mineral density (vBMD) over 110 days even though animal weight does not change [38, 39]. Two Gy of gamma irradiation in $\mathrm{C} 3 \mathrm{H} /$ $\mathrm{HeN}$ mice decreases the trabecular bone volume fraction and BMD as early as 12 weeks post-irradiation [40]. In contrast, the delivery of $4.4 \mathrm{cGy}$ to the appendicular skeleton (a subset of the 60 Gy delivered to the head) of immunocompetent $\mathrm{C} 57 \mathrm{Bl} / 6$ mice results in a remarkable increase in trabecular BV/TV 11.5 months after exposure [41].

For X-ray radiation there are still potential issues for normal $\mu \mathrm{CT}$ imaging protocols. Increased scan doses may be required if high resolutions are needed for accurate bone morphology measurements [42]. These doses can alter the experimental outcomes. A $712 \mathrm{mGy}$ dose delivered almost weekly $(1,2,3$, and 5 weeks) to immunocompetent $\mathrm{C} 3 \mathrm{H} /$ $\mathrm{HeJ}, \mathrm{C} 57 \mathrm{Bl} / 6 \mathrm{~J}$, or BALB/cByJ mice both with and without ovariectomy (OVX) results in a trabecular BV/TV decrease, but immunocompetent Wistar rats imaged every other week do not show the same effect [43]. Similarly, imaging immunocompetent Wistar rats weekly with a dose between 441 and 939 mGy over a 7-week period does not change the trabecular BV/TV [44]. For mice, the time interval might be more critical. One study reports a $30 \%$ loss in trabecular $\mathrm{BV} / \mathrm{TV}$ of immunocompetent $\mathrm{C} 57 \mathrm{Bl} / 6$ mice with three 776 mGy scans separated by 2 -week intervals, but not when the dose per scan was reduced to 434 mGy [45].

The radiation-induced changes detected in these $\mu \mathrm{CT}$ imaging studies are probably reflective of phenomena that are more systemic and cellular in nature. Single 15-20 Gy doses of X-rays delivered to the abdomen of immunocompetent $\mathrm{C} 57 \mathrm{Bl} / 6$ mice results in a BMD decrease in the femur and tibia as early as 7 days post-radiation [46]. The same study also reports a weight decrease 5-7 days after irradiation, similar to other data indicating a significant weight decrease in immunocompetent $\mathrm{C} 57 \mathrm{Bl} / 6$ and $\mathrm{BALB} / \mathrm{c}$ SCID mice 3 days after a 3.36 Gy dose [23]. Both a 0.5 and 2 Gy whole body dose of X-ray radiation to immunocompetent $\mathrm{C} 57 \mathrm{Bl} / 6 \mathrm{JJcl}$ mice results in fewer bone marrow cells as early as 1 day post-exposure [47], and a 2 Gy whole body dose of X-rays to immunocompetent $\mathrm{C} 57 \mathrm{Bl} / 6$ mice increases osteoclast number as early as 3 day post-exposure [48]. Osteophytes can occur with a whole body dose as low as 3 Gy in immunocompetent Fisher F344 X Brown Norway rats, and cartilage degradation worsens as dose increases [49]. Localized dose delivery can also be problematic. Both 5 and 20 Gy of X-rays delivered to one limb of immunocompetent Balb/c mice induces alopecia and erythema, and results in a dose dependent decrease in trabecular BV/TV 6 weeks post-irradiation [50]. Trabecular bone volume losses in both irradiated and the non-radiated contralateral tibiae 10 days after a 2 Gy dose of X-ray radiation localized to the limb of immunocompetent $\mathrm{C} 57 \mathrm{Bl} / 6$ mice is also associated with a body weight decrease attributed to fat loss, increased marrow adiposity, increased number of osteoclasts, and reduced bone formation rate [51].

Commercially available pharmaceuticals may be able to help prevent the effects of radiation-induced bone loss from $\mathrm{X}$-rays. Treatment with the anti-catabolic bisphosphonate risedronate results in an increased trabecular BV/TV 3 weeks after a 2 Gy dose of X-rays to immunocompetent C57B1/6 mice, even though the radiation alone reduces $\mathrm{BV} / \mathrm{TV}$ and vBMD as early as 1 week and decreases the bone formation 
rate starting at 2 weeks [52]. The anabolic agent parathyroid hormone (PTH) 1-34 increases vBMD and BV/TV starting 4 days after treatment in immunocompetent Sprague Dawley rats, even though the 0.48 Gy dose delivered during daily imaging decreases vBMD and BV/TV without PTH [53].

\section{Dose Effects: Oncology Applications}

Damage from accumulated radiation is a particular concern in cancer research, especially since longitudinal monitoring is often essential for tracking tumor progression [34, 54-56]. Given that radiotherapy is a common approach for treating cancer, it is not surprising that high local doses of radiation can reduce tumor volume [57-59]. This must be done with caution. Doses of 2-4 Gy of gamma radiation to hepatocellular carcinoma cells in vitro can increase the stemness of cancer cells after 7-14 days [60]. A single 30 Gy X-ray dose delivered directly to a tumor causes a significant upregulation of genes associated with angiogenesis and downregulation of genes for eukaryotic initiation factors [61]. This may be related to changes in vascularity. A single 20 Gy dose of $\mathrm{X}$-ray radiation to sarcomas in transgenic mice increases the fractional blood volume and dextran accumulation within a sarcoma after just 4 days [57]. This is about the same timepoint at which vasculature within a tumor begins to reform [61]. The MET oncogene is upregulated in vitro by a 10 Gy dose of X-rays with the resulting cells being able to migrate easier [62]. A 5 Gy dose to subcutaneous tumors implanted in athymic nude mice may be sufficient to induce DNA damage in a tumor and induce a growth delay [59]. However, a 3 Gy dose of X-rays delivered locally to xenografts implanted in nonobese diabetic-severe combined immunodeficient (NOD/SCID) mice results in a significant weight loss by the 5th day post-irradiation [58], and 310 Gy of X-ray radiation to cancer cells in vitro may induce tumor cells to repopulate [63].

Lower radiation doses that are more common in imaging procedures can also be problematic. X-ray doses as low as $0.25-2$ Gy induce intestinal and colon tumors in genetically prone immunocompetent mice in an age and straindependent fashion [64]. Doses as low as $0.3-0.5$ Gy to human microvascular endothelial cells (HMVEC) can induce molecular markers of vascular formation, especially in a simulated hypoxic environment, and this can lead to increased angiogenesis in athymic swiss $\mathrm{Nu} / \mathrm{Nu}$ mice and an increased tumor burden 14 days later in an orthotopic NOD/ SCID murine model [65]. Performing a $\sim 1$ Gy scan in a metastatic tumor model using athymic nude mice once weekly over a 5-week period increased leg metastasis and the histological tumor area nearly two-fold [56]. Conversely, although high-resolution scans may kill tumor cells, when the imaging protocols are designed to manage dose there may not be a detrimental effect on bone tumor growth with weekly scans of athymic nude mice over a 4-week study [54]. Doses of 0.07-0.30 Gy every 4 days during a routine imaging procedure also do not change the volume of subcutaneous tumors implanted in immunocompetent C57B1/6 mice after 16 days [55].

Radiation effects on the immune system may also need to be considered in oncology studies utilizing $\mu \mathrm{CT}$ imaging. Many preclinical oncology studies use SCID mice which have increased radiosensitivity and a defective DNA repair mechanism $[26,66]$. Tumors derived from SCID mice are more susceptible to high doses of radiation than tumors derived from $\mathrm{C} 3 \mathrm{H}$ mice [25], which may be related to endothelial biology [67]. Conversely, translational oncology studies that use immunocompetent rodent strains are becoming increasingly important as immunotherapies that impact NK, T, and B cells of the immune system gain traction [68]. Individual cytokines like IL-1 $\beta$ that are relevant in immune system signaling may be upregulated by high doses of X-ray radiation [69]. At doses more relevant to in vivo $\mu \mathrm{CT}$ imaging, $0.1 \mathrm{~Gy}$ of $80 \mathrm{kVp} \mathrm{X}$-ray radiation significantly alters gene regulation in these immunological pathways [70]. Immunologically relevant cytokines and the cytolytic activity of NK cells and macrophages is also increased in response to a single dose of 0.1 or 0.2 Gy of X-rays, which can potentially act as a radioprotectant by reducing subsequent tumor burden [71].

\section{Dosimetry Methods}

Given these complicated effects and interactions, it is clearly important to have a precise understanding of radiation dose within a scan. In clinical environments, several standards have been implemented to ensure reproducibility and patient safety [72-75]. Unfortunately, there is no similar standard for preclinical research. A number of different techniques have been applied in the literature. The simplest and most widely accepted approach is to use an ionization chamber $[10,13,28,29,33,39,43-45,55,58,76-79]$. This data can then be used to calculate the CT dose index $\left(\mathrm{CTDI}_{100}\right)$ as is commonly done in clinical environments. Gafchromic films can be used to develop a depth profile if more detailed information is needed $[14,23,61,80]$. Others have implanted thermoluminescence dosimeters (TLDs) or nanoDots near specific organs within an animal to measure the doses at specific locations [14, 29, 42, 76, 77, 81-87]. The most complete map of dose in every tissue requires Monte-Carlo-based simulations, although the implementation complexity and variability in the results makes these techniques challenging to reproduce $[10,29,35,36,76]$.

In light of the complex relationships between dose and experimental outcomes, to help guide proper study design and application of $\mu \mathrm{CT}$ imaging methodologies, the purpose of this work is to characterize dose on the Quantum GX and provide a framework for protocol selection. Ionization chambers are used to measure the dose at the center of $\mathrm{x}$ ray beam and $\mathrm{CTDI}_{100}$ on the rotation axis. The results can be appropriately used in a translational context. Doses from 
Table 1. Specifications of the Quantum GX imaging system that are used in $\mathrm{CTDI}_{100}$ calculations

\begin{tabular}{ll}
\hline Specification & Value \\
\hline Detector pixel pitch & $49.5 \mu \mathrm{m}$ \\
Number of rows on detector (z-axis) & 2352 \\
Number of columns on detector $(x, y$-axes) & 2944 \\
Source to detector distance (SDD) & $203 \mathrm{~mm}$ \\
Source to object distance (SOD), high & $55 \mathrm{~mm}$ \\
$\quad$ magnification (36mm acquisition FOV) & $108 \mathrm{~mm}$ \\
\hline SOD, low magnification (72 mm acquisition FOV) & \\
\hline
\end{tabular}

other $\mu \mathrm{CT}$ imaging systems will also be described to provide some context for where this newer system compares with other scanners used in the scientific literature.

\section{Experimental Design and Methods}

\section{Scanner Configuration}

The Quantum GX uses a complementary metal-oxide semiconductor (CMOS)-based flat-panel detector. Various imaging modes within the scanner enable this to be used with bin modes of 1,2 , or 4 . The flat panel detector is mounting on an adjustable magnification mechanism which, in turn, is mounted on a rotating gantry. This adjustable magnification mechanism allows the source to object distance to be modified, enabling a broader range of applications to suit both high-resolution and low-dose applications. The source to detector distance is fixed. The actual distances and detector specifications are reported in Table 1.

The microfocus X-ray source in this scanner is limited to a maximum voltage of $90 \mathrm{kVp}$ and a maximum power of $8 \mathrm{~W}$. The X-ray source uses a Tungsten anode. A fixed filter of $0.5 \mathrm{~mm} \mathrm{Al}$ and $0.06 \mathrm{~mm} \mathrm{Cu}$ is placed in front of the exit port to remove low energy X-rays that contribute to dose but do not improve image quality.

\section{Half Value Layer Measurements}

The half value layer (HVL), defined as the thickness of aluminum that reduces the radiation energy by $50 \%$, was measured to get a sense of the X-ray beam quality. A meter was placed at isocenter of the X-ray beam on a sample bed normally used for rat imaging (Piranha 657, RTI Electronics $\mathrm{AB})$. Data were measured for voltage settings of 50, 60, 70, 80 , and $90 \mathrm{kVp}$. Both the measured voltage and half value layer were reported.

\section{Dosimetry Measurements}

Two cylindrical phantoms were made from polymethyl methacrylate (PMMA) with outer diameters of 20 and $32 \mathrm{~mm}$ (Fig. 1a) to mimic attenuation from a mouse and rat, respectively, similar to previously reported studies [76]. The inner diameter of $12.54 \mathrm{~mm}$ was made to fit the $10-\mathrm{cm}$ long pencil ionization chamber used for dosimetry measurements. The phantom length was $15 \mathrm{~cm}$ to be consistent with clinical dosimetry practices [75].

To make the measurements, the ionization chamber was either placed directly on the sample bed or slid into the phantom before being centered on the sample bed. The sample bed was then moved so that the center of the ionization chamber was aligned with the z-center of the X-ray beam (Fig. 1b). A dose measurement was then made for a fixed tube power of $7.9 \mathrm{~W}$ at voltage of 50, 70, or $90 \mathrm{kVp}$. Measurements were made in triplicate and the mean value was used for reporting doses. A schematic set-up for the dose measurement in low magnification scanning mode is shown in Fig. 1c.

A Thimble chamber (Model $10 \times 5-0.6 \mathrm{CT}$, Radcal Inc., Monrovia, CA, USA) was used to measure the dose at the center of the $\mathrm{x}$-ray beam on the rotation axis. The chamber has an active length of $21 \mathrm{~mm}$ and an active volume of $0.6 \mathrm{~cm}^{3}$. A pencil ionization chamber (Model 10X5-3CT, Radcal Inc., Monrovia, CA, USA) was used to measure $\mathrm{CTDI}_{100}$ on the rotation axis. Both chambers have flat energy response with about $4 \%$ variation over half value layers (HVL) between 1.6 and $10 \mathrm{~mm}$ of aluminum (Radcal Calibration Laboratory Personal Communication) Each chamber was connected to a dose monitor (Model 9015, Radcal Inc., Monrovia, CA, USA) for reading out. The calibration of the dosimeter system was traceable to the National Institute of Standards and Technology (NIST).

\section{CTDI ${ }_{100}$ Calculation}

Once the raw measurements were completed, $\mathrm{CTDI}_{100}$ was calculated as defined in units of mGy using the equation

$$
\mathrm{CTDI}_{100}=\frac{1}{N^{*} T} \int_{-50 \mathrm{~mm}}^{50 \mathrm{~mm}} D(z) \mathrm{dz}
$$

where $N$ is defined as the number of slices, $T$ is defined as the slice thickness at ISO, and $D(z)$ is the dose profile along the $z$-axis (Fig. 1c). The product of $N^{*} T$ is effectively the beam width in the $z$-direction at the isocenter. Because the ionization chamber measures an average exposure (in units of $\mathrm{mR}$ ), the f-factor was included to convert the exposure to the actual absorbed dose in air (in units of rad) and converted into mGy. $\mathrm{CTDI}_{100}$ measurements were then normalized to $\mathrm{mA} \times \mathrm{s}$ based on the acquisition times. The f-factor of $0.87 \mathrm{rad} / \mathrm{R}$ was used [74]. Even though this value is noted for $120 \mathrm{kVp}$, the same value will be used for the softer beams here because the responses are almost constant with respect to energy [88].

\section{Image Acquisition and Analysis for Application Examples}

Images of mice and phantoms were obtained to study the relationship between dose and image quality. For animal 

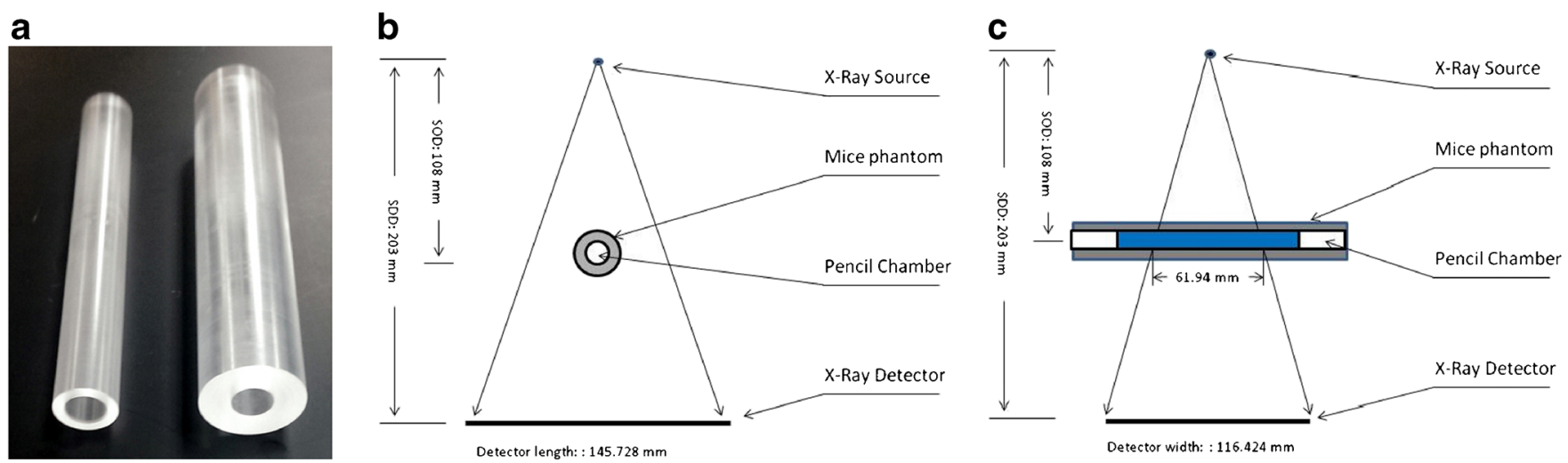

Fig. 1 a PMMA phantoms placed around the ionization chamber for measuring doses relative to a mouse and rat. $\mathbf{b}$ Front view of dose measurement set-up in low magnification mode showing the system geometry listed in Table 1. c Side view of dose measurement set-up in normal mode. The total $\mathrm{x}$-ray beam width at rotation axis is defined as $N \times T \times \mathrm{SOD} / \mathrm{SDD}$, where the parameters are defined in Table 1. For the low magnification mode shown here this equates to $0.0495 \times 2352 \times 108 /$ $203=61.94 \mathrm{~mm}$. For the high magnification mode (not shown) this equates to $0.0495 \times 2352 \times 55 / 203=31.543 \mathrm{~mm}$.

images, 7-month old immunocompetent female BALB/c mice were used. One mouse was scanned at peak X-ray tube voltages of 50,70 , and $90 \mathrm{kVp}$ for the shortest scan time using the low magnification. A second mouse was scanned at $90 \mathrm{kVp}$ using all available scan times applicable for in vivo imaging, and then a single slice was reconstructed at the highest allowable resolution. A ring reduction correction was applied to the sinograms, and the resulting corrected sinograms were input into a GPU-based filtered-backprojection reconstruction algorithm using a Ram-Lak filter. Images were then imported into Analyze 12.0 (AnalyzeDirect, Overland Park, KS) and calibrated to be on the Hounsfield unit (HU) scale. A segmentation map was created using semi-automatic segmentation tools to select voxels of bone, adipose tissue, lung parenchyma, and general soft tissue (areas of the GI tract containing food were excluded). This segmentation map was then applied to each image to calculate the mean $\mathrm{HU}$ value for each tissue type. The contrast to noise ratio (CNR) was also calculated for each tissue type. Contrast was defined as the difference between the mean value of tissue and the mean grayscale value of the animal bed. Noise was defined as the standard deviation of air. All experiments were done under the approval of an institutional animal care and use committee.

Two separate phantoms were also scanned at a peak Xray tube voltage of $90 \mathrm{kVp}$ to explore the relationships between dose and image quality. The first phantom was a $32 \mathrm{~mm}$ diameter low contrast phantom that contains 1 and $2.5 \mathrm{~mm}$ diameter rods embedded in resin at an approximate contrast 4 and $8 \% \mathrm{HU}$ (QRM-MicroCT-LC, QRM GmBH, Möhrendorf, Germany). The second phantom was a $32 \mathrm{~mm}$ diameter hydroxyapatite (HA) phantom typically used for bone mineral density calibrations that contains materials equivalent to $0,50,200,800$, and $1200 \mathrm{mg} / \mathrm{cm}^{3}$ of $\mathrm{HA}$ embedded in resin (QRM-MicroCT-HA, QRM GmBH, Möhrendorf, Germany). The scan times were selected to be both $18 \mathrm{~s}$ and $2 \mathrm{~min}$, two protocols in the Quantum GX which use a $2 \times 2$ detector binning mode. A ring reduction correction was applied to the sinogram, and the resulting corrected sinogram was input into a GPU-based filteredbackprojection reconstruction algorithm using a Ram-Lak filter to create the 3D images. Images were then imported into Analyze 12.0, calibrated to be on the HU scale, and visualized.

\section{Results}

\section{Quantum GX Dose Measurements}

Half value layer measurements ranged from $1.56 \mathrm{~mm} \mathrm{Al}$ for $50 \mathrm{kVp}$ up to $2.6 \mathrm{~mm} \mathrm{Al}$ for $90 \mathrm{kVp}$ (Table 2). The HVL measurements increase as a function of peak X-ray source voltage. As confirmed by the dosimeter vendor Radcal, the energy dependency of the ionization chambers is flat in the measured HVL range with a maximum variation of $4 \%$.

The measured $\mathrm{CTDI}_{100}$ per mAs at the center of x-ray beam on the rotation axis are shown in Table 3. For both the low- and high-magnification modes, the difference between the measured $\mathrm{CTDI}_{100}$ in air, in the mouse phantom, and in the rat phantom is less than $13 \%$ for a given $\mathrm{kVp}$ setting. Interestingly, for $90 \mathrm{kVp}$ with the low magnification, the dose rate increased slightly in comparison to air when the mouse phantom was used but decreases again when the rat phantom was used. Dose rates are also a function of the peak $\mathrm{X}$-ray voltage. The $\mathrm{CTDI}_{100}$ for $70 \mathrm{kVp}$ are $36-40 \%$ lower than at $90 \mathrm{kVp}$. The $\mathrm{CTDI}_{100}$ for $50 \mathrm{kVp}$ are $70-73 \%$ lower than at $90 \mathrm{kVp}$. The middle point dose in air was measured at $7.0 \mathrm{mGy} / \mathrm{mA}^{*}$ s for a $70 \mathrm{kVp}$ beam and $11.8 \mathrm{mGy} / \mathrm{mA}^{*} \mathrm{~s}$ for a $90 \mathrm{kVp}$ beam.

For the shortest 8-s scan time on the Quantum GX, at $90 \mathrm{kVp}$ the dose floor (defined as the lowest possible dose for a particular configuration) is 39.8 and $9.9 \mathrm{mGy}$, 
Table 2. X-ray source settings and half value layer measurements

\begin{tabular}{lcccc}
\hline $\begin{array}{l}\text { Voltage } \\
\text { setting }(\mathrm{kVp})\end{array}$ & $\begin{array}{l}\text { Current } \\
\text { setting (uA) }\end{array}$ & $\begin{array}{l}\text { Tube } \\
\text { power }(\mathrm{W})\end{array}$ & $\begin{array}{l}\text { Measured } \\
\text { voltage }(\mathrm{kVp})\end{array}$ & $\begin{array}{l}\mathrm{HVL} \\
(\mathrm{mm} \mathrm{Al})\end{array}$ \\
\hline 50 & 158 & 7.90 & 49.57 & 1.56 \\
60 & 133 & 7.98 & 60.24 & 1.71 \\
70 & 114 & 7.98 & 70.18 & 1.96 \\
80 & 100 & 8.00 & 79.93 & 2.26 \\
90 & 88 & 7.92 & 89.35 & 2.60 \\
\hline
\end{tabular}

respectively, for the high and low magnifications in air. The dose floor reduced slightly to $9.4 \mathrm{mGy}$ when the $32 \mathrm{~mm}$ PMMA phantom was used. Reducing the tube voltage to $50 \mathrm{kVp}$ changes the dose floor to 21.0 and $5.1 \mathrm{mGy}$, respectively, for the high and low magnifications in air.

\section{Application Examples}

A series of example images were acquired to provide context for interpreting how dose may impact applications. For screening applications that typically use the low-dose protocols, a single mouse was scanned using a range of common X-ray source voltages. A segmentation map of bone, adipose tissue, soft tissue, and lung parenchyma were created and applied to each of the images (Fig. 2). There is an increase in contrast of bone as the voltage decreases (Table 4). There was no measureable change in HU value as a function of voltage for adipose tissue, soft tissue, or lung parenchyma. The noise level and CNR did change slightly for soft tissue and lung parenchyma as a function of voltage. There were changes for bone applications that typically require high resolution and necessitate higher doses, a single mouse was scanned using a range of scan times and the best resolution image possible for each scan time was reconstructed (Fig. 3). There is a significant increase in anatomical detail as the scan time increases and as the physical magnification increases.

To provide an example of how dose relates to image quality for a given detector bin mode, voltage and physical magnification, two separate phantoms were scanned. In a low-contrast phantom, a $1 \mathrm{~mm}$ insert with an approximate HU contrast $4 \%$ was not visible with a 18 -s scan but was visible with a 2-min scan (Fig. 4a, b). All other rods in the phantom were much easier to visualize when the scan time
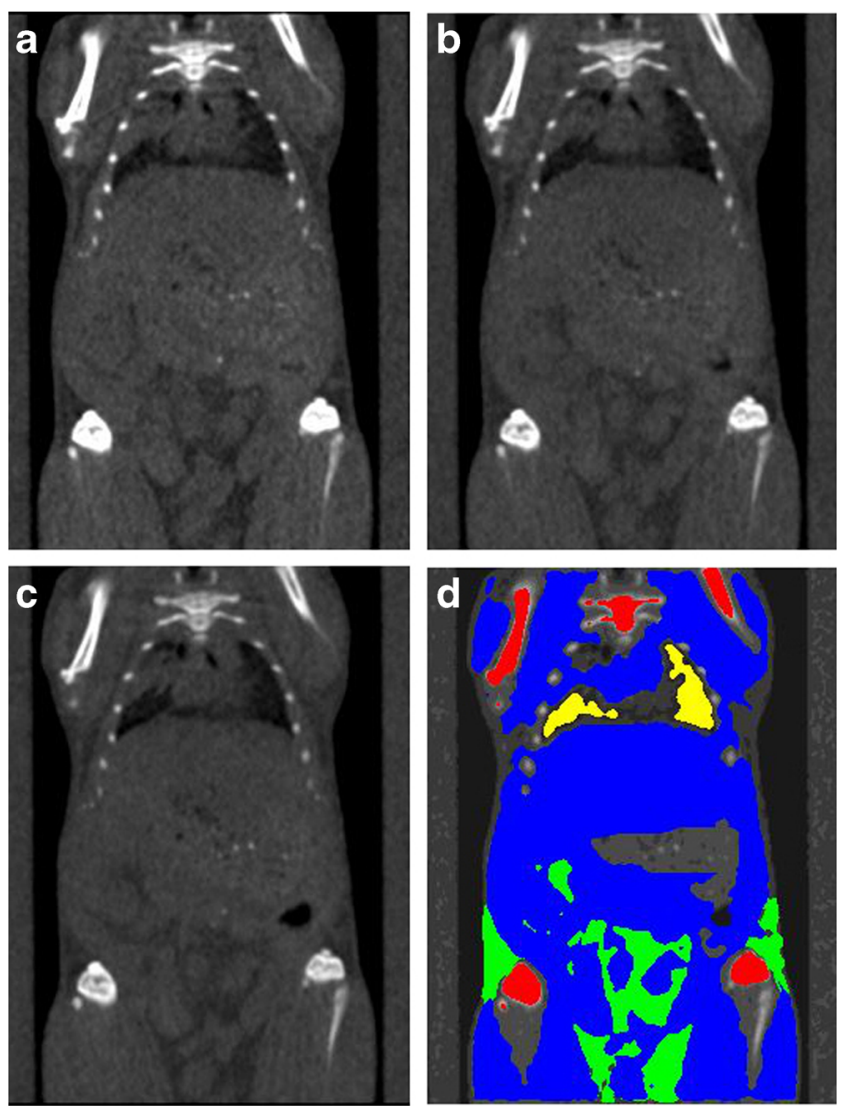

Fig. 2 Example coronal slices showing the shortest 8-s scan using the low magnification for peak X-ray source voltages and doses of a $50 \mathrm{kVp}$ and $5.0 \mathrm{mGy}$ with a noise level of $38 \mathrm{HU}, \mathbf{b} 70 \mathrm{kVp}$, and $7.8 \mathrm{mGy}$ with a noise level of $34 \mathrm{HU}$, and c $90 \mathrm{kVp}$, and $10.0 \mathrm{mGy}$ with a noise level of $32 \mathrm{HU}$. Doses were calculated using the $\mathrm{CTDI}_{100}$ measurements for the mouse equivalent phantom. d The bone (red), lung parenchyma (yellow), adipose tissue (green) and soft tissue (b/ue) were segmented, and the mean grayscale values for each mask were calculated (Table 4). The Gl tract was specifically excluded because chow could potentially bias the soft tissue grayscale value. All images are displayed with a level of $750 \mathrm{HU}$ and a window of $2500 \mathrm{HU}$, and filtered with a $3 \times 3 \times 3$ low pass filter to reduce noise.

increased. For a HA phantom that contains a range of mineral density equivalents, all four inclusions containing HA could be easily visualized at both scan times (Fig. 4c, d).

Table 3. Dose rate measurements on the Quantum GX $\mu \mathrm{CT}$ imaging system

\begin{tabular}{lllll}
\hline Magnification & Environment & \multicolumn{2}{l}{$\mathrm{CTDI}_{100}$ measurements (mGy/mA*s) } & \\
\cline { 3 - 4 } & & $50 \mathrm{kVp}, 158 \mathrm{uA}(7.90 \mathrm{~W})$ & $70 \mathrm{kVp}, 113 \mathrm{uA}(7.91 \mathrm{~W})$ & $90 \mathrm{kVp}, 88 \mathrm{uA}(7.92 \mathrm{~W})$ \\
\hline Low (72 mm FOV) & Air & 3.49 & 7.72 & 12.07 \\
& 20 mm PMMA (mouse) & 3.38 & 7.33 & 12.21 \\
High (36 mm FOV) & Air & 3.12 & 3.89 & 11.48 \\
& 20 mm PMMA (mouse) & 14.31 & 13.74 & 48.65 \\
& 32 mm PMMA (rat) & 12.45 & 29.53 & 47.57 \\
\hline
\end{tabular}


Table 4. Grayscale values in HU (mean \pm sd) and CNR for the images shown in Fig. 2

\begin{tabular}{|c|c|c|c|c|c|c|}
\hline \multirow[t]{2}{*}{ Tissue type } & \multicolumn{2}{|l|}{$50 \mathrm{kVp}$} & \multicolumn{2}{|l|}{$70 \mathrm{kVp}$} & \multicolumn{2}{|l|}{$90 \mathrm{kVp}$} \\
\hline & Grayscale / & CNR & Grayscale & CNR & Grayscale & CNR \\
\hline Adipose & $-23 \pm 96$ & -1.7 & $-40 \pm 74$ & -2.4 & $-42 \pm 71$ & -2.4 \\
\hline Soft tissue & $159 \pm 84$ & 3.0 & $116 \pm 68$ & 2.2 & $92 \pm 62$ & 1.7 \\
\hline Lung parenchyma & $-275 \pm 80$ & -8.3 & $-298 \pm 79$ & -9.9 & $-308 \pm 77$ & -10.6 \\
\hline Bone & $2118 \pm 650$ & 54.3 & $1623 \pm 502$ & 46.4 & $1339 \pm 438$ & 40.4 \\
\hline
\end{tabular}

\section{Dose from Other Scanners}

In order to have context for the dose data for the Quantum GX imaging system, a literature review was performed to get a sense of the doses reported for other similar instrumentation (Table 5). Dosimetry methodologies vary and can have considerable impact on how the dose is reported, so the methods used are noted along with the data. Many instruments have a wide range of doses reported because there is considerable flexibility in how the system is used. A dose floor below $10 \mathrm{mGy}$ is reported for two instruments (BioScan nanoSPECT/CT and Aloka LaTheta LCT-200), below 100 mGy for five instruments (GammaMedica X-O, GE CT120, GE Locus Ultra, Imtek MicroCAT II, Siemens Inveon), and above $100 \mathrm{mGy}$ for three instruments (ScanCo vivaCT40, Skyscan 1076, Skyscan 1178) (Table 4). Comparing performance between systems is difficult because of differences in system design and the lack of a standardized approach. Therefore, the primary application for each publication was collated. While there is a considerable range of doses, orthopedics applications generally have higher doses while applications in general radiology for soft tissue screening typically have lower doses. It should be noted that other systems are available and that various manufacturers
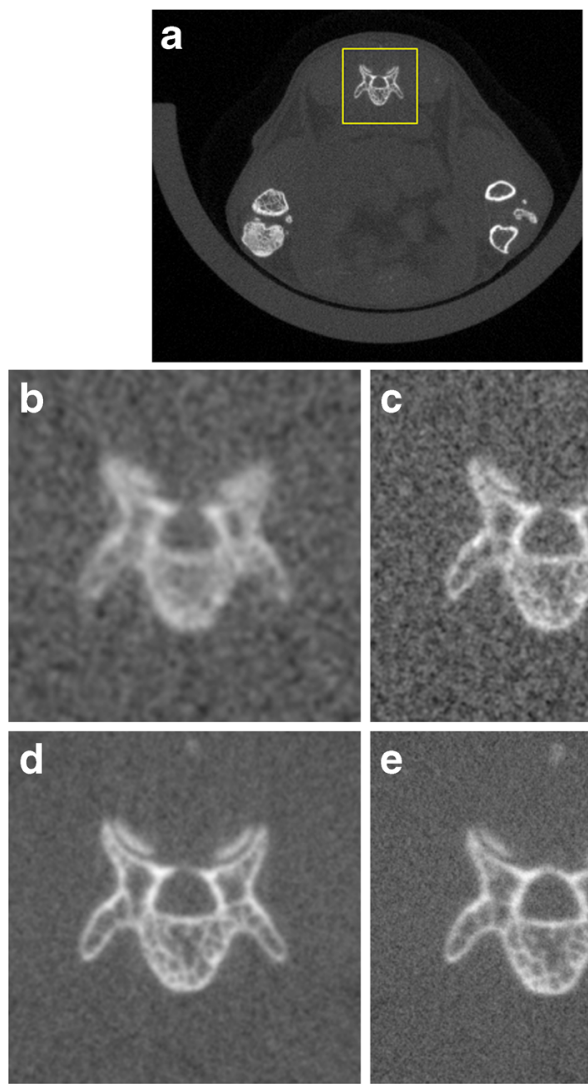
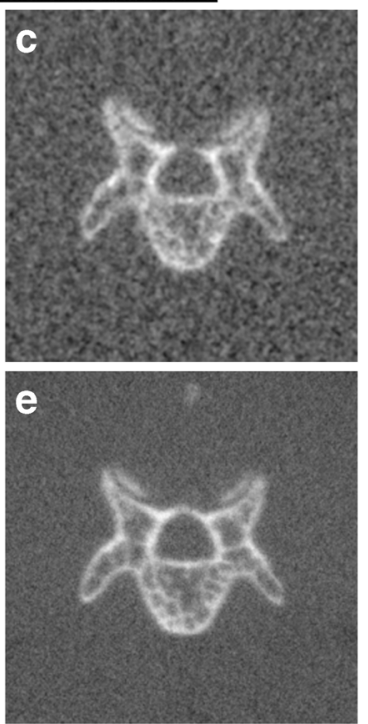
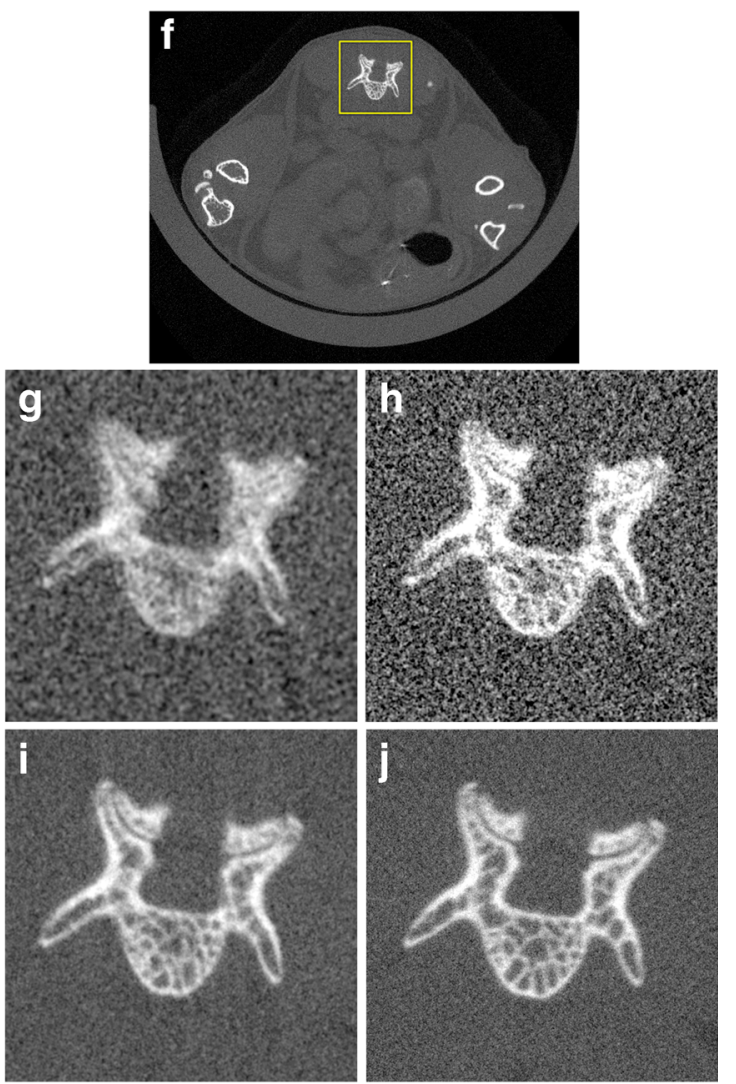

Fig. 3 Example images of a transaxial rostral slice through L6 showing subvolume reconstructions at the highest resolution possible. a The low magnification was then cropped (yellow box) for display purposes to show the b 8-s scan, $36 \mu \mathrm{m}$ isotropic voxel size, $10 \mathrm{mGy}$, c 18-s scan, $18 \mu \mathrm{m}$ isotropic voxel size, $22.4 \mathrm{mGy}, \mathbf{d} 2$-min scan, $18 \mu \mathrm{m}$ isotropic voxel size, $130.4 \mathrm{mGy}$, or e 4-min scan, $9 \mu \mathrm{m}$ isotropic voxel size, $269.1 \mathrm{mGy}$. $\mathbf{f}$ The high magnification was then cropped (box) for display purposes to show the $\mathbf{g}$ 8-s scan, $18 \mu \mathrm{m}$ isotropic voxel size, $38.9 \mathrm{mGy}, \mathbf{h} 18 \mathrm{~s}$ scan, $9 \mu \mathrm{m}$ isotropic voxel size, $87.1 \mathrm{mGy}$, i 2-min scan, $9 \mu \mathrm{m}$ isotropic voxel size, 508.2 mGy, or $\mathbf{j} 4-\mathrm{min}$ scan, $4.5 \mu \mathrm{m}$ isotropic voxel size, $1048.2 \mathrm{mGy}$. All images are displayed with a level of $1000 \mathrm{HU}$ and a window of $4000 \mathrm{HU}$ with no filtering applied. 

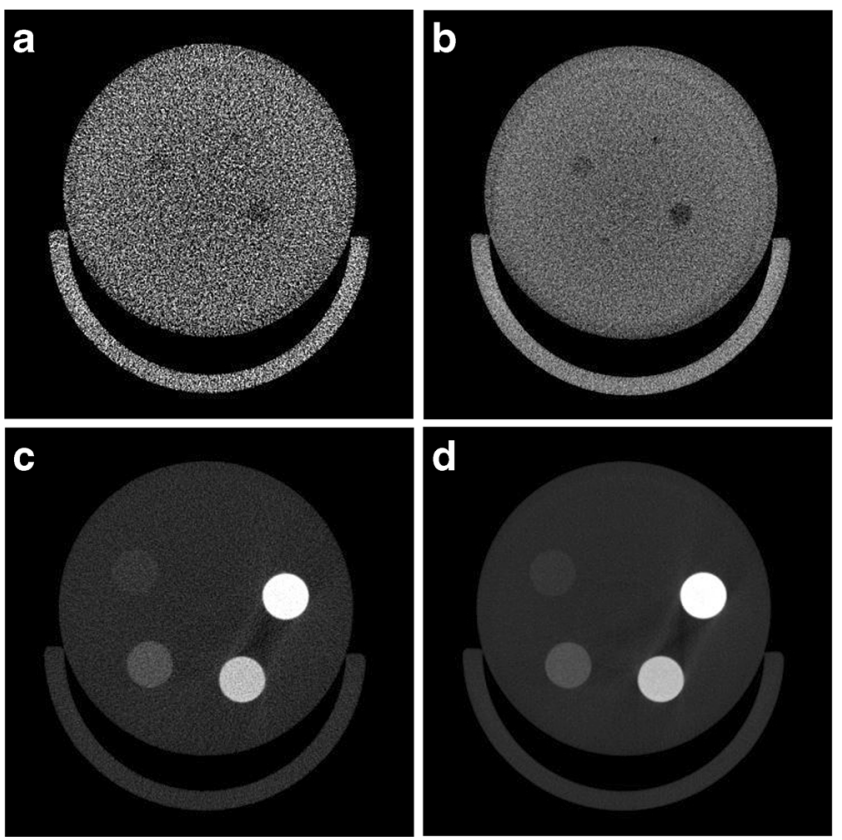

Fig. 4 Comparisons of $\mathbf{a}, \mathbf{b}$ a low contrast phantom displayed with level of $0 \mathrm{HU}$ and a window of $400 \mathrm{HU}$ and c, d a HA phantom displayed with a level of $1000 \mathrm{HU}$ and a window of $3000 \mathrm{HU}$. The images were acquired with either a, c an 18 s, 22.4 mGy scan or b, d a 2 min, 130.4 mGy scan using $2 \times 2$ binning on the detector, a $90 \mathrm{kVp}$ X-ray source voltage and the low physical magnification. Increasing the dose by increasing the scan time enables visualization of all four inclusions in the low contrast phantom. All four inclusions were visible in the HA phantom at either scan time.

may have different data than what is presented here. The data reported in Table 5 is based solely on peer-reviewed publications.

\section{Discussion}

The lowest dose preclinical systems use doses on the same order of magnitude as the $1-10 \mathrm{mSv}$ values typically reported in clinical CT [89]. These doses are considered to be manageable in longitudinal studies. For example, scanning mice three times weekly for a 4-week period with a 16 mGy protocol does not impact body weight, organ weights, or hematological readouts either acutely or when followed by a 4-week latency period [79]. The dosimetry data presented in this study indicate that the Quantum GX has a dose floor that is also within the range of clinical CT systems. For the typical 'recommended' voltage of $90 \mathrm{kVp}$, although there is a wide range of possible doses depending on the imaging mode chosen, the lowest dose is $9.9 \mathrm{mGy}$. This is similar to two other instruments showing doses below $10 \mathrm{mGy}$ and, in itself, is a conservative estimate because it is based solely on the air kerma rate. The PMMA phantom results indicate that the dose may decrease slightly when mice or rats are scanned. The slight increase in
$\mathrm{CTDI}_{100}$ in the low magnification when switching from air to the mouse PMMA phantom may indicate a slight increase in scatter that is then absorbed when the thicker rat PMMA phantom is used.

HVL data for the Quantum GX is comparable to the $2.5 \mathrm{~mm} \mathrm{Al} \mathrm{HVL}$ of another preclinical $\mu \mathrm{CT}$ system that uses a $80 \mathrm{kV}$ beam [81]. More importantly for this study, this range is consistent with other radiographic imaging equipment, so ionization chambers are generally applicable. Doses for the lower energies (50 and $70 \mathrm{kVp}$ ) may be up to $4 \%$ underreported because the typical clinical CT systems have a slightly higher typical HVL [90], but for HVL values above approximately $2.0(80-90 \mathrm{kVp})$ the dosimetry data can be considered accurate. This is reinforced by the similarity between the thimble chamber measurements and the ionization chamber measurements. The dose floor of the Quantum GX is also consistent with other preclinical instrumentation. Direct head to head comparisons between the various preclinical instruments are quite difficult because the system designs differ widely. Differences between the instruments in physical geometry, X-ray beam quality, and operating modes (voltages, scan times, etc.) all have a significant effect on dose. Differences in the detective quantum efficiency due to the scintillator, optical coupling, and sensor type (e.g., charge-coupled device (CCD), CMOS, amorphous $\mathrm{Si}$ ) also significantly impact how the radiation dose affects image quality in a projection image. Reconstruction implementations including the type of algorithm (e.g., filtered backprojection, iterative) and filter kernel also impact the quality of the reconstructed 3D image. However, the comparative data available in the literature still provide a valuable reference point for understanding what is common within preclinical imaging.

Some preclinical applications may be achievable with low-dose protocols, but some applications may require higher-dose imaging protocols. For general whole body screening, the Quantum GX provides excellent image quality with the lowest dose 50,70 , and $90 \mathrm{kVp}$ protocols. The decrease in contrast for bone tissue in a mouse as the $\mathrm{X}$ ray source voltage increases is consistent with reduced attenuation as the HVL increases. The lack of measurable changes in contrast of adipose tissue, soft tissue, and lung parenchyma as a function of voltage suggests that the HVL may need to be reduced further to increase contrast for these tissues. Alternatively, as demonstrated using a low-contrast phantom, switching to a higher-dose acquisition protocol can help improve the contrast to noise ratio for visualizing lowcontrast structures. However, the ability to visualize bone and $\mathrm{HA}$ at $90 \mathrm{kVp}$ indicates that low-dose acquisitions may be sufficient for some applications. However, if skeletal morphology needs to be measured, using a higher-dose protocol can substantially improve the ability to resolve small structures [42].

There are also applications specific approaches for gating in cardiopulmonary imaging that can affect dose. Prospective gating methods theoretically have equivalent dose to 
Table 5. Dose measurements for $\mu \mathrm{CT}$ imaging systems reported in the peer-reviewed literature

\begin{tabular}{|c|c|c|c|c|}
\hline CT instrument & Dosimetry methods & Imaging application Area & Doses reported & Ref. \\
\hline BioScan nanoSPECT/CT & EBT2 gafchromic films & Multi-modality, oncology & 8.3-3361 mGy & [23] \\
\hline $\begin{array}{l}\text { CT Imaging TomoScope dual } \\
\text { source scanner }\end{array}$ & $\begin{array}{l}\mathrm{CTDI}_{100} \text { (ionization chamber) } \\
\text { LiF TLDs } \\
\text { Monte Carlo simulations }\end{array}$ & General & $153-200$ mGy & {$[76]$} \\
\hline Gamma Medica X-O & (Not reported) & Pulmonology & 63.6 mGy & [91] \\
\hline Gamma Medica X-SPECT/CT & (not reported) & Multi-modality, oncology & $\sim 1000 \mathrm{mGy}$ & [56] \\
\hline Gamma Medica X-SPECT/CT & LiF TLDs & Oncology & 14-134 mGy & [85] \\
\hline GE CT120 & $\mathrm{CTDI}_{100}(\mathrm{MOSFET})$ & General & $20.15-56.79$ mGy & [101] \\
\hline GE CT120 & Monte Carlo simulations & General & $\begin{array}{l}\text { Whole body, mouse: } 67-189 \mathrm{mGy} \\
\text { Whole body, rat: } 42-119 \mathrm{mGy}\end{array}$ & [36] \\
\hline GE eXplore Locus & LiF TLDs & General & 126-229 mGy & [87] \\
\hline GE Locus Ultra & Ionization chamber & General & 64-270 mGy & [13] \\
\hline GE Locus Ultra & Ionization chamber & Oncology & 69-296 mGy & [55] \\
\hline GE RS—90 & Ionization chamber & Pulmonology & $\begin{array}{l}\text { Ungated: } 120 \mathrm{mGy} \\
\text { Gated: } 150 \mathrm{mGy}\end{array}$ & [78] \\
\hline Imtek MicroCAT & TLDs & Oncology & Organs: $210-760$ mGy & [86] \\
\hline Imtek (Siemens) MicroCAT II & $\begin{array}{l}\text { LiF TLDs } \\
\text { ionization chamber }\end{array}$ & General & $\begin{array}{l}\text { Air: } 78-97 \mathrm{mGy} \\
\text { Organ: } 65-86 \mathrm{mGy}\end{array}$ & [81] \\
\hline Imtek (Siemens) MicroCAT II & NanoDot & General & 11-104.5 mGy & [83] \\
\hline Imtek (Siemens) MicroCAT II & TLDs & General & Air: $55.6-61.5 \mathrm{mGy}$ & [84] \\
\hline LaTheta LCT-200 & TLDs & Contrast agents & 5-40 mGy & [15] \\
\hline $\begin{array}{l}\text { Rigaku RmCT2 (PerkinElmer } \\
\text { Quantum FX) }\end{array}$ & FGDs & General & 16 mGy & [79] \\
\hline ScanCo vivaCT40 & Ionization chamber & Whole body scanning (mice) & $\begin{array}{l}\text { Polymer: } 712.4 \mathrm{mGy} \\
\text { Air: } 845.9 \mathrm{mGy}\end{array}$ & {$[43]$} \\
\hline ScanCo vivaCT 40 & CTDI (ionization chamber) & Orthopedics & $\begin{array}{l}\text { Air: } 939 \text { mGy } \\
\text { Polymer: } 441 \mathrm{mGy}\end{array}$ & [44] \\
\hline Siemens Inveon & TLDs & Orthopedics & $40-1257 \mathrm{mGy}$ & [42] \\
\hline Siemens Inveon & NanoDot & General & Organs: $9.4-163.1 \mathrm{mGy}$ & [83] \\
\hline Skyscan 1076 & (Not reported) & Orthopedics & $400 \mathrm{mGy}$ & [102] \\
\hline Skyscan 1076 & $\begin{array}{l}\text { Ionization chamber } \\
\text { TLDs } \\
\text { Monte Carlo }\end{array}$ & Pulmonology & $\begin{array}{l}\text { Ionization chamber: } 1640 \mathrm{mGy} \\
\text { TLDs, skin: } 1104 \mathrm{mGy} \\
\text { TLDs, lung: } 813 \mathrm{mGy} \\
\text { Monte Carlo, organs: } 900 \mathrm{mGy}-4.5 \mathrm{~Gy}\end{array}$ & [29] \\
\hline SkyScan 1076 & Ionization chamber & Orthopedics & 166,434 or $776 \mathrm{mGy}$ & [45] \\
\hline Skyscan 1178 & $\begin{array}{l}\text { CTDI }_{100} \text { (ionization chamber) } \\
\text { LiF TLDs }\end{array}$ & General & Organs: 295-507 mGy & {$[77]$} \\
\hline X-Strahl SARRP & (Not reported) & Radiotherapy planning & 16,32 or $64 \mathrm{mGy}$ & [103] \\
\hline Custom dual energy system & Not reported-data unpublished & Oncology & $260 \mathrm{mGy}$ & [57] \\
\hline
\end{tabular}

ungated protocols, although the dose for respiratory applications may still increase approximately $25 \%$ in practice [78]. This is still much lower than retrospective methods that require oversampling and increase dose in comparison to prospective methods [91]. However, this is often acceptable because the retrospective methods will work for variable respiration rates, whereas prospective methods assume that the respiration interval is constant during the entire scan. The only way to ensure that dose for ungated and gated acquisitions are identical is to intubate and mechanically ventilate so that the same protocol can be used [92]. Cardiac gating methods face similar challenges, although the dose for cardiac gated acquisitions can also be lowered if image analysis approaches are designed that are robust against the image quality reductions which occur [93].

There are several possible approaches to reducing dose in the future versions of the Quantum GX. First, because this dose is for an operating mode where data is acquired over 360 degrees, optimizations to use a half scan protocol could reduce this even further [94]. Second, the data presented here suggest that the dose could be reduced quite considerably by switching from $90 \mathrm{kVp}$ to lower voltages and still provide excellent image quality for certain applications. Although the expected gain in soft tissue contrast was not obvious for the shortest 8-s scan time, $50 \mathrm{kVp}$ has been used using the earlier generation Quantum FX for adipose imaging [95], so the lower voltages may still be useful for soft tissue quantification. Further optimizations of the X-ray filters that either reduce the HVL and increase soft tissue contrast, or increase the HVL and further reduce dose, are also plausible. There are also several software improvements that can potentially reduce dose. Clinical CT systems now use fairly sophisticated image reconstruction algorithms, but most $\mu \mathrm{CT}$ systems still use variations of the filtered-backprojection methods initially reported several decades ago [96]. Recent research indicates that more advanced reconstruction methods can be employed which allow the number of projections to be reduced, thereby reducing the required X-ray dose [97, 98].

In the clinical CT environment, the Image Wisely ${ }^{\circledR}$ and Image Gently ${ }^{\circledR}$ initiatives help ensure that the ALARA principle is followed [99, 100]. However, there is no similar 
initiative or any widely accepted standard in the preclinical research environment. Investigators must find an acceptable image quality (e.g., SNR, spatial resolution) that can be achieved with the lowest possible dose for each experiment. Specific experimental variables should be considered when designing any $\mu \mathrm{CT}$ study including (but not necessarily limited to) the following:

- Animal strain: Some strains have a higher radiosensitivity. Given that some animal models require specific mice strains and/or necessitate the use of immune deficient animals, any concerns specific to the strain should be tracked during the study.

- Animal gender and age: The biological response to radiation-induced damage is mediated by molecular pathways. There is experimental evidence of age specific responses to ionizing radiation, so it is worth considering both in study design.

- Tissue of interest: Local absorbed doses can vary significantly from tissue to tissue. While a particular dose may not necessarily affect one tissue (e.g., lung), it may have an impact on other tissues that absorb more local dose (e.g., bone) and both tissue types are usually exposed to radiation during a scan.

- Imaging timepoints: Some radiation-induced damage can be repaired at the molecular level. Therefore, the frequency of imaging should be considered carefully and minimized as much as possible within the context of a particular experimental hypothesis.

- Outcome metric: Some purely anatomical measurements may be less correlated to radiation-induced damage. However, damage may still be occurring at the cellular and molecular levels. This may be acceptable in some studies, but should be considered carefully particularly when a molecular-based pathology is being studied and/ or when subsequent research will require investigating cellular and molecular mechanisms. This should also be considered carefully when pathologies which are inherently systemic (e.g., metastatic cancer) are being investigated.

\section{Conclusions}

In conclusion, $\mu \mathrm{CT}$ imaging techniques are invaluable in many research studies and have been widely used. The Quantum GX imaging system has a beam quality comparable to other $\mu \mathrm{CT}$ imaging systems and provides range of protocols which enable a wide range of possible radiation doses. Selecting the best imaging protocol is not trivial. Doses can be chosen which are quite low to avoid any radiation damage, but some applications will require higher doses. There is some conflicting data in specific studies, but the complex downstream effects of radiation-induced damage make it important carefully manage radiation doses when using these techniques. Simple metrics like body weight are important to track and may uncover some underlying systemic changes when frequent longitudinal imaging is required. Including additional experimental groups with a significantly reduced radiation exposure can also provide some assurance that the radiation dose effects do not adversely impact interpretation of the data. When all of these considerations are properly balanced, $\mu \mathrm{CT}$-based imaging techniques can be properly managed to provide all the benefits of in vivo imaging.

\section{Compliance with Ethical Standards}

\section{Conflict of Interest}

Jeff Meganck is an employee of PerkinElmer.

Bob Liu was a paid consultant for the dose measurements in this work.

Open Access This article is distributed under the terms of the Creative Commons Attribution 4.0 International License (http:// creativecommons.org/licenses/by/4.0/), which permits unrestricted use, distribution, and reproduction in any medium, provided you give appropriate credit to the original author(s) and the source, provide a link to the Creative Commons license, and indicate if changes were made.

\section{References}

1. Goldman M (1982) Ionizing radiation and its risks. West J Med 137:540-547

2. Mitchell MJ, Logan PM (1998) Radiation-induced changes in bone. Radiographics 18:1125-1136; quiz 1242-1243

3. Shah DJ, Sachs RK, Wilson DJ (2012) Radiation-induced cancer: a modern view. Br J Radiol 85:e1166-e1173

4. Schambach SJ, Bag S, Schilling L et al (2010) Application of micro$\mathrm{CT}$ in small animal imaging. Methods 50:2-13

5. Clark DP, Badea CT (2014) Micro-CT of rodents: state-of-the-art and future perspectives. Phys Medica 30:619-634

6. Niska JA, Meganck JA, Pribaz JR et al (2012) Monitoring bacterial burden, inflammation and bone damage longitudinally using optical and $\mu \mathrm{CT}$ imaging in an orthopaedic implant infection in mice. PLoS One 7:e47397

7. Cronin M, Akin AR, Collins SA et al (2012) High resolution in vivo bioluminescent imaging for the study of bacterial tumour targeting. PLoS One 7:e30940

8. Hsieh J (2009) Computed tomography: principles, design, artifacts and recent advances, 2nd edn. SPIE, Bellingham, WA

9. Hubbell JH, Seltzer SM (2016) Tables of X-ray Mass Attenuation Coefficients and Mass Energy-Absorption Coefficients from $1 \mathrm{keV}$ to $20 \mathrm{MeV}$ for Elements $\mathrm{Z}=1$ to 92 and 48 Additional Substances of Dosimetric Interest. http://www.nist.gov/pml/data/xraycoef/

10. Boone JM, Velazquez O, Cherry SR (2004) Small-animal X-ray dose from micro-CT. Mol Imaging 3:149-158

11. Ford NL, Thornton MM, Holdsworth DW (2003) Fundamental image quality limits for microcomputed tomography in small animals. Med Phys 30:2869-2877

12. Mcnitt-Gray MF (2004) Tradeoffs in Image Quality and Radiation Dose for CT. In: AAPM 46th Annu. Meet. Pittsburgh, PA, p 2328

13. Du LY, Umoh J, Nikolov HN et al (2007) A quality assurance phantom for the performance evaluation of volumetric micro-CT systems. Phys Med Biol 52:7087-7108

14. Jermoumi M, Korideck H, Bhagwat M et al (2015) No comprehensive quality assurance phantom for the small animal radiation research platform (SARRP). Phys Medica 31:529-535

15. Stiller W, Kobayashi M, Koike K et al (2007) Initial experience with a novel low-dose micro-CT system. Rofo 179:669-675

16. Welch D, Harken AD, Randers-Pehrson G, Brenner DJ (2015) Construction of mouse phantoms from segmented CT scan data for radiation dosimetry studies. Phys Med Biol 60:3589-3598

17. Anuranjani BM (2014) Concerted action of Nrf2-ARE pathway, MRN complex, HMGB1 and inflammatory cytokines-implication in modification of radiationdamage. Redox Biol 2:832-846 
18. Costes SV, Chiolo I, Pluth JM et al (2010) Spatiotemporal characterization of ionizing radiation induced DNA damage foci and their relation to chromatin organization. Mutat Res 704:78-87

19. Willers H, Dahm-Daphi J, Powell SN (2004) Repair of radiation damage to DNA. Br J Cancer 90:1297-1301

20. Jeggo P, Löbrich M (2006) Radiation-induced DNA damage responses. Radiat Prot Dosim 122:124-127

21. Metheetrairut C, Slack F (2013) MicroRNAs in the ionizing radiation response and in radiotherapy. Curr Opin Genet Dev 23:12-19

22. Martin LM, Marples B, Lynch TH et al (2014) Exposure to low dose ionising radiation: molecular and clinical consequences. Cancer Lett 349:98-106

23. Kersemans V, Thompson J, Cornelissen B et al (2011) Micro-CT for anatomic referencing in PET and SPECT: radiation dose, biologic damage, and image quality. J Nucl Med 52:1827-1833

24. Rübe CE, Grudzenski S, Kühne M et al (2008) DNA double-strand break repair of blood lymphocytes and normal tissues analysed in a preclinical mouse model: implications for radiosensitivity testing. Clin Cancer Res 14:6546-6555

25. Budach W, Hartford A, Gioioso D et al (1992) Tumors arising in SCID mice share enhanced radiation sensitivity of SCID normal tissues. Cancer Res 52:6292-6296

26. Iwakawa M, Noda S, Ohta $\mathrm{T}$ et al (2003) Different radiation susceptibility among five strains of mice detected by a skin reaction. J Radiat Res 44:7-13

27. Workman P, Aboagye EO, Balkwill F et al (2010) Guidelines for the welfare and use of animals in cancer research. Br J Cancer 102:15551577

28. Detombe SA, Dunmore-Buyze J, Petrov IE, Drangova M (2013) Xray dose delivered during a longitudinal micro-CT study has no adverse effect on cardiac and pulmonary tissue in C57BL/6 mice. Acta Radiol 54:435-441

29. Vande Velde G, De Langhe E, Poelmans J et al (2015) Longitudinal in vivo micro-computed tomography of mouse lungs: no evidence for radiotoxicity. Am J Physiol Lung Cell Mol Physiol 309:L271-L279

30. Hong Z-Y, Eun SH, Park K et al (2014) Development of a small animal model to simulate clinical stereotactic body radiotherapyinduced central and peripheral lung injuries. J Radiat Res 55:648-657

31. Hong ZY, Lee CG, Shim HS et al (2016) Time, dose, and volume responses in a mouse pulmonary injury model following ablative irradiation. Lung 194:81-90

32. Saito S, Murase K (2012) Detection and early phase assessment of radiation-induced lung injury in mice using micro-CT. PLoS One 7:e45960

33. Jacob RE, Murphy MK, Creim JA, Carson JP (2013) Detecting radiation-induced injury using rapid $3 \mathrm{D}$ variogram analysis of $\mathrm{CT}$ images of rat lungs. Acad Radiol 20:1264-1271

34. Perez BA, Ghafoori AP, Lee C-L et al (2013) Assessing the radiation response of lung cancer with different gene mutations using genetically engineered mice. Front Oncol 3:72

35. Taschereau R, Chow PL, Chatziioannou AF (2006) Monte Carlo simulations of dose from microCT imaging procedures in a realistic mouse phantom. Med Phys 33:216-224

36. Bretin F, Bahri MA, Luxen A et al (2015) Monte Carlo simulations of the dose from imaging with GE eXplore 120 micro-CT using gate. Med Phys 42:5711

37. Swift JM, Swift SN, Smith JT et al (2015) Skin wound trauma, following high-dose radiation exposure, amplifies and prolongs skeletal tissue loss. Bone 81:487-494

38. Hamilton SA, Pecaut MJ, Gridley DS et al (2006) A murine model for bone loss from therapeutic and space-relevant sources of radiation. J Appl Physiol 101:789-793

39. Bandstra ER, Pecaut MJ, Anderson ER et al (2008) Long-term dose response of trabecular bone in mice to proton radiation. Radiat Res 169:607-614

40. Lee J-H, Lee H-J, Yang M et al (2013) Establishment of a murine model for radiation-induced bone loss using micro-computed tomography in adult $\mathrm{C} 3 \mathrm{H} / \mathrm{HeN}$ mice. Lab Anim Res 29:55-62

41. Karim L, Judex S (2014) Low level irradiation in mice can lead to enhanced trabecular bone morphology. J Bone Miner Metab 32:476483
42. Arentsen L, Hui S (2013) Characterization of rotating gantry microCT configuration for the in vivo evaluation of murine trabecular bone. Microse Microanal 19:907-913

43. Klinck RJ, Campbell GM, Boyd SK (2008) Radiation effects on bone architecture in mice and rats resulting from in vivo micro-computed tomography scanning. Med Eng Phys 30:888-895

44. Brouwers JEM, Van Rietbergen B, Huiskes R (2007) No effects of in vivo micro-CT radiation on structural parameters and bone marrow cells in proximal tibia of wistar rats detected after eight weekly scans. J Orthop Res 25:1325-1332

45. Laperre K, Depypere M, van Gastel N et al (2011) Development of micro-CT protocols for in vivo follow-up of mouse bone architecture without major radiation side effects. Bone 49:613-622. doi:10.1016/ j.bone.2011.06.031

46. Jia D, Gaddy D, Suva LJ, Corry PM (2011) Rapid loss of bone mass and strength in mice after abdominal irradiation. Radiat Res 176:624635

47. Murakami S, Yoshino H, Ishikawa J et al (2015) Effects of ionizing radiation on differentiation of murine bone marrow cells into mast cells. J Radiat Res 56:865-871

48. Willey JS, Lloyd SAJ, Robbins ME et al (2008) Early increase in osteoclast number in mice after whole-body irradiation with 2 Gy X rays. Radiat Res 170:388-392

49. Hutchinson ID, Olson J, Lindburg CA et al (2014) Total-body irradiation produces late degenerative joint damage in rats. Int J Radiat Biol 90:821-830

50. Wernle JD, Damron TA, Allen MJ, Mann KA (2010) Local irradiation alters bone morphology and increases bone fragility in a mouse model. J Biomech 43:2738-2746

51. Wright LE, Buijs JT, Kim H-S et al (2015) Single-limb irradiation induces local and systemic bone loss in a murine model. J Bone Miner Res 30:1268-1279

52. Willey JS, Livingston EW, Robbins ME et al (2010) Risedronate prevents early radiation-induced osteoporosis in mice at multiple skeletal locations. Bone 46:101-111

53. Chandra A, Lan S, Zhu J et al (2013) PTH prevents the adverse effects of focal radiation on bone architecture in young rats. Bone 55:449457

54. Johnson LC, Johnson RW, Munoz SA et al (2011) Longitudinal live animal micro-CT allows for quantitative analysis of tumor-induced bone destruction. Bone 48:141-151

55. Foster WK, Ford NL (2011) Investigating the effect of longitudinal micro-CT imaging on tumour growth in mice. Phys Med Biol 56:315326

56. Cowey S, Szafran AA, Kappes J et al (2007) Breast cancer metastasis to bone: evaluation of bioluminescent imaging and microSPECT/CT for detecting bone metastasis in immunodeficient mice. Clin Exp Metastasis 24:389-401

57. Moding EJ, Clark DP, Qi Y et al (2013) Dual energy micro-CT imaging of radiation-induced vascular changes in primary mouse sarcomas. Int J Radiat Oncol Biol Phys 85:1353-1359

58. Lee CJ, Spalding AC, Ben-Josef E et al (2010) In vivo bioluminescent imaging of irradiated orthotopic pancreatic cancer xenografts in nonobese diabetic-severe combined immunodeficient mice: a novel method for targeting and assaying efficacy of ionizing radiation. Transl Oncol 3:153-159

59. Tuli R, Surmak A, Reyes J et al (2012) Development of a novel preclinical pancreatic cancer research model: bioluminescence imageguided focal irradiation and tumor monitoring of orthotopic xenografts. Transl Oncol 5:77-84

60. Ghisolfi L, Keates $\mathrm{AC}, \mathrm{Hu} \mathrm{X}$ et al (2012) Ionizing radiation induces stemness in cancer cells. PLoS One 7:e43628

61. Maeda A, Leung MKK, Conroy L et al (2012) In vivo optical imaging of tumor and microvascular response to ionizing radiation. PLoS One 7:e42133

62. De Bacco F, Luraghi P, Medico E et al (2011) Induction of MET by ionizing radiation and its role in radioresistance and invasive growth of cancer. J Natl Cancer Inst 103:645-661

63. Allen C, Tinganelli W, Sharma N et al (2015) DNA damage response proteins and oxygen modulate prostaglandin E2 growth factor release in response to low and high LET ionizing radiation. Front Oncol $5: 260$ 
64. Okamoto M, Yonekawa H (2005) Intestinal tumorigenesis in Min mice is enhanced by $\mathrm{X}$-irradiation in an age-dependent manner. $\mathrm{J}$ Radiat Res 46:83-91

65. Sofia Vala I, Martins LR, Imaizumi N et al (2010) Low doses of ionizing radiation promote tumor growth and metastasis by enhancing angiogenesis. PLoS One 5:e11222

66. Biedermann KA, Sun JR, Giaccia AJ et al (1991) scid mutation in mice confers hypersensitivity to ionizing radiation and a deficiency in DNA double-strand break repair. Proc Natl Acad Sci U S A 88:13941397

67. García-Barros M, Thin TH, Maj J et al (2010) Impact of stromal sensitivity on radiation response of tumors implanted in SCID hosts revisited. Cancer Res 70:8179-8186

68. Borghaei H, Smith MR, Campbell KS (2009) Immunotherapy of cancer. Eur J Pharmacol 625:41-54

69. Nemoto K, Ishihara H, Tanaka I et al (1995) Expression of IL-1 beta mRNA in mice after whole body X-irradiation. J Radiat Res 36:125133

70. Luzhna L, Kovalchuk O (2014) Low dose irradiation profoundly affects transcriptome and microRNAme in rat mammary gland tissues. Oncoscience 1:751-762

71. Nowosielska EM, Cheda A, Wrembel-Wargocka J, Janiak MK (2010) Immunological mechanism of the low-dose radiation-induced suppression of cancer metastases in a mouse model. Dose-Response 8:209-226

72. International Commission on Radiation Units and Measurements (2012) ICRU Report No. 87: radiation dose and image-quality assessment in computed tomography. J ICRU 12:1-149

73. AAPM Task Group 2 (1993) Specification and Acceptance Testing of Computed Tomography Scanners. AAPM Rep. 39

74. AAPM Task Group 23 (2008) The Measurement, Reporting, and Management of Radiation Dose in CT. AAPM Rep. NO. 96

75. AAPM Task Group 3 (2010) Comprehensive Methodology for the Evaluation of Radiation Dose in X-ray Computed Tomography. AAPM Rep. 111

76. Hupfer M, Kolditz D, Nowak T et al (2012) Dosimetry concepts for scanner quality assurance and tissue dose assessment in micro-CT. Med Phys 39:658

77. Willekens I, Buls N, Lahoutte T et al (2010) Evaluation of the radiation dose in micro-CT with optimization of the scan protocol. Contrast Media Mol Imaging 5:201-207

78. Cavanaugh D, Johnson E, Price RE et al (2004) In vivo respiratorygated micro-CT imaging in small-animal oncology models. Mol Imaging 3:55-62

79. Miyahara N, Kokubo T, Hara Y et al (2016) Evaluation of X-ray doses and their corresponding biological effects on experimental animals in cone-beam micro-CT scans (R-mCT2). Radiol Phys Technol 9:60-68

80. Bazalova M, Graves E (2016) MicroCT dose and image quality for in vivo microCT systems. Unpubl. data

81. Figueroa SD, Winkelmann CT, Miller HW et al (2008) TLD assessment of mouse dosimetry during microCT imaging. Med Phys 35:3866-3874

82. Hui SK, Fairchild GR, Kidder LS et al (2013) The influence of therapeutic radiation on the patterns of bone remodeling in ovaryintact and ovariectomized mice. Calcif Tissue Int 92:372-384
83. Osborne DR, Yan S, Stuckey A et al (2012) Characterization of X-ray dose in murine animals using microCT, a new low-dose detector and nanodot dosimeters. PLoS One 7:e49936

84. Obenaus A, Smith A (2004) Radiation dose in rodent tissues during micro-CT imaging. J X-Ray Sci Technol 12:241-249

85. Carlson SK, Classic KL, Bender CE, Russell SJ (2007) Small animal absorbed radiation dose from serial micro-computed tomography imaging. Mol Imaging Biol 9:78-82

86. Paulus MJ, Gleason SS, Kennel SJ et al (2000) High resolution X-ray computed tomography: an emerging tool for small animal cancer research. Neoplasia 2:62-70

87. Rodt T, Luepke M, Boehm C et al (2011) Phantom and cadaver measurements of dose and dose distribution in micro-CT of the chest in mice. Acta Radiol 52:75-80

88. Johns HE, Cunningham JR (1969) The Physics of Radiology, 3rd ed. Thomas

89. US Food and Drug Administration (2016) What are the Radiation Risks from CT? http://www.fda.gov/Radiation-EmittingProducts/ RadiationEmittingProductsandProcedures/MedicalImaging/MedicalXRays/ucm115329.htm

90. Maia AF, Caldas LVE (2006) A simple method for evaluation of halfvalue layer variation in CT equipment. Phys Med Biol 51:1595-1601

91. Farncombe TH (2008) Software-based respiratory gating for small animal conebeam CT. Med Phys 35:1785-1792

92. Bartling SH, Kuntz J, Semmler W (2010) Gating in small-animal cardio-thoracic CT. Methods 50:42-49

93. Badea CT, Wetzel AW, Mistry N et al (2008) Left ventricle volume measurements in cardiac micro-CT: the impact of radiation dose and contrast agent. Comput Med Imaging Graph 32:239-250

94. Parker DL (1982) Optimal short scan convolution reconstruction for fanbeam CT. Med Phys 9:254-257

95. Donato AJ, Henson GD, Hart CR et al (2014) The impact of ageing on adipose structure, function and vasculature in the $\mathrm{B} 6 \mathrm{D} 2 \mathrm{~F} 1$ mouse: evidence of significant multisystem dysfunction. J Physiol 592:4083-4096

96. Feldkamp LA, Davis LC, Kress JW (1984) Practical cone-beam algorithm. J Opt Soc Am A 1:612

97. Vandeghinste B, Vandenberghe S, Vanhove C et al (2013) Low-dose micro-CT imaging for vascular segmentation and analysis using sparse-view acquisitions. PLoS One 8:e68449

98. Han X, Bian J, Eaker DR et al (2011) Algorithm-enabled low-dose micro-CT imaging. IEEE Trans Med Imaging 30:606-620. doi:10.1109/TMI.2010.2089695

99. Image Wisely (2016) Radiation Safety in Adult Medical Imaging. http://www.imagewisely.org/

100. Image Gently (2014) The Alliance for Radiation in Pediatric Imaging. http://www.imagegently.org/

101. Bretin F, Warnock G, Luxen A et al (2013) Performance evaluation and X-ray dose quantification for various scanning protocols of the GE eXplore 120 micro-CT. IEEE Trans Nucl Sci 60:3235-3241

102. Waarsing JH, Day JS, Van Der Linden JC et al (2004) Detecting and tracking local changes in the tibiae of individual rats: a novel method to analyse longitudinal in vivo micro-CT data. Bone 34:163-169

103. Yang Y, Armour M, Wang KK-H et al (2015) Evaluation of a cone beam computed tomography geometry for image guided small animal irradiation. Phys Med Biol 60:5163-5177 